\title{
Association Between Chinese Herbal Medicine (CHM) Treatment and Depression Among Cancer Patients in a Cross-sectional Study
}

Huiyue Lin

shang hai zhong yi yao da xue fu shu long hua yi yuan: Long Hua Hospital https://orcid.org/00000001-7948-2097

\section{Xueting Zhang}

shang hai zhong yi yao da xue fu shu long hua yi yuan: Long Hua Hospital

\section{Yi Zhang}

shang hai zhong yi yao da xue fu shu long hua yi yuan: Long Hua Hospital

\section{Wenjing Cui}

shang hai zhong yi yao da xue fu shu long hua yi yuan: Long Hua Hospital

\section{Fang Jia}

shang hai zhong yi yao da xue fu shu long hua yi yuan: Long Hua Hospital

Juyong Wang ( $\nabla$ wangjuyong1@126.com )

shang hai zhong yi yao da xue fu shu long hua yi yuan: Long Hua Hospital

\section{Research Article}

Keywords: Chinese herbal medicine(CHM), cancer patients, depression, health-related quality of life, Cross-sectional Study

Posted Date: December 23rd, 2021

DOI: https://doi.org/10.21203/rs.3.rs-1055621/v1

License: (c) (1) This work is licensed under a Creative Commons Attribution 4.0 International License. Read Full License 


\section{Abstract}

Aim: This study was undertaken to investigate the relationship between Chinese Herbal Medicine treatment and depression in cancer patients.

Methods: A cross-sectional study was conducted among cancer outpatients at Longhua Hosiptal Shanghai University of Traditional Chinese Medicine from June 2020 to April 2021; Ethical approval number:2020LCSY057). All patients signed informed consent and completed The European Organization for Research and Treatment of Cancer Quality of Life Questionnaire. Hamilton depression scale was evaluated depression by psychiatrists. The software packages $\mathrm{R}$ and EmpowerStats were used for statistical analysis.

Results: 374 was enrolled in Received Chinese Herbal Medicine treatment group and 435 was enrolled in Non-received Chinese Herbal Medicine treatment group. The assessment results of Hamilton depression scale and the European Organization for Research and Treatment of Cancer Quality of Life Questionnaire in Received Chinese Herbal Medicine treatment group were better than Non-received Chinese Herbal Medicine treatment group. After adjusting potential confounders (gender, medical insurance, cancer stage, et al), Chinese Herbal Medicine treatment indicated negative correlation with depression ( $\mathrm{OR}=0.7$, $95 \%$ confidence interval $(\mathrm{Cl}): 0.5$ to 0.9$)$. The interactions in each subgroup were no significantly effect on the relationship between Chinese Herbal Medicine treatment and depression.

Conclusion: Chinese Herbal Medicine treatment was an independent protective factor for depression in cancer patients, and lead to better quality of life for cancer patients.

\section{Introduction}

According to the World Health Organization. Global Cancer Observatory, it approximately accounted for 19.29 million new cases of all cancers and deaths from cancer internationally were over 9.9 million in 2020. Among them, the number of cancer cases and deaths in China were about 4.5 million and 3.0 million respectively, ranking first in the world ${ }^{[1]}$. Psychological was one factor of causes for malignant tumors that affect the occurrence and development of malignant tumors in addition to physical, chemical, biological and genetic factors. As early as 1957, American scholars conducted a 20-year followup study on the workers of the Western Power Company and founded that those who were emotionally depressed or emotionally unstable are more likely to get malignant tumors ${ }^{[2]}$. Later in 2000 , Studies had shown that negative emotions would affect the occurrence and development of malignant tumors through psychological and physiological mechanisms ${ }^{[3]}$. Therefore, unhealthy mood will affect the occurrence and development of tumors.

Now with the acceleration of development in modern society, people had mostly unhealthy emotions such as depression. Depression were common on cancer patient. Prevalence rates for depression in patients with cancer range from $1.5 \%$ to $50 \%$ as three to five times higher than the rates observed in the 
general population ${ }^{[4]}$. Cancer could increase patients' susceptibility to depression in several ways. There were treatment side effects such as chemotherapy and radiotherapy caused depression in addition to the stressor of cancer diagnosis and complications of cancer. These conventional treatments for cancer couldn't eradicate the cancer and couldn't be used continuously. So cancer patients would feel abandoned and isolated while stopping or being unable to withstand conventional treatments for cancer which also could exacerbate symptoms such as depression ${ }^{[5]}$. The comorbid state of cancer and depression would incrementally deteriorate health even further. Current research pointed out depression was an independent risk factor for cancer mortality with estimates as high as a $26 \%$ greater mortality rate among patients with depressive symptoms ${ }^{[6]}$. Meanwhile depression would affect the quality of life, compliance to treatment, disease advancement in cancer patients ${ }^{[7]}$. Thence, it is essential to find ways of improving depression, thereby enhance the level of QOL prolong longevity for cancer survivors.

Traditional Chinese Medicine (TCM) was China's unique medical model which has widely viewed as an important complementary and alternative medicine (CAM) with beneficial effects for cancer patients in China. TCM, especially Chinese herbal medicine (CHM) plays a critical role in sustaining cancer patients "survival with cancer" [8-9]. CHM were regarded as an alternative therapy in a lot of cancer outpatients for its effectiveness and lack of serious side effects ${ }^{[9]}$.The effect of anti-cancer for $\mathrm{CHM}$ were worked through various chemical components, multi-targets and multiple pharmacological effects ${ }^{[10]}$.

Currently, there are no relevant reports about the relationship between $\mathrm{CHM}$ treatment and depression in cancer patients. Consequently our study preliminary explore the relationship between $\mathrm{CHM}$ treatment and depression in cancer patients which aimed for better understanding the depression of cancer patients and the influence of $\mathrm{CHM}$ on the depression.

\section{Patients And Methods}

\section{Study population}

A total of 809 cancer outpatients were recruited and selected according to exclusion standard in this cross-sectional study at Longhua Hosiptal Shanghai University of Traditional Chinese Medicine from June 2020 to April 2021. Exclusion standards: (1) diagnosed cancer without cytological or pathological examination; (2) Those who have lost clinical data; (3) Poor communication; (4)mental disorders caused by central nervous system disease; (5) Taking psychotropic drugs at present; (6)current hyperthyroidism, hypothyroidism. The study conducted according to the Declaration of Helsinki principles and was approved by the the Ethics Committee of Longhua Hospital Shanghai University of Traditional Chinese Medicine, Shanghai, PRC (Approval Number: 2020LCSY057). All outpatients were thoroughly briefed on the goals and processes of the study and signed informed consent.

\section{Hamilton depression scale (HAMD)}


The depression status of all outpatients were assessed by HAMD-24 ${ }^{[11]}$, which had been widely used to assess depression in Chinese clinical practice. HAMD-24 includes seven items: anxiety/somatization, weight loss, diurnal variation, cognitive disturbance, retardation, sleep disturbance, and depression. The HAMD-24 was investigated by two trained psychiatrists through face-to-face interview. Cancer patients whose HAMD scores rise above 8 was judged to have depressive symptoms.

\section{Health-related quality of life (HRQoL)}

The European Organization for Research and Treatment of Cancer (EORTC) Core Quality of Life Questionnaire (QLQ-C30) were developed and extensively used in clinical trials ${ }^{[12]}$. EORTC QLQC30(Chinese version 3.0) were the Chinese version of EORTC QLQ-C30 and defined as a valid instrument to assess the quality of life of Chinese patients with cancer ${ }^{[13]}$. functional scales as physical, role, emotional, cognitive and social, symptom sub-scales as pain, fatigue, nausea and vomiting, global health condition sub-scale and individual measurement items as appetite, insomnia, dyspnea, constipation or diarrhea and economic status. HRQoL was assessed using EORTC QLQ-C30(Chinese version 3.0) questionnaire through outpatients filling in by themselves. Those who were illiterate or have difficulty writing can complete the questionnaire with the assistance of doctor. Based the EORTC Scoring Manual, standardized HRQoL scores on a 0 to 100 scale. A high score reflected a high functional level, high global quality of life level, and high symptomatic level[14].

\section{Statistical analysis}

Normal distribution variables were described as mean \pm SD and used to determine any statistical differences by One-Way Anova; Skewed distribution variables were showed as median (quartile) which used Mann-Whitney test to determine any statistical differences; Qualitative variables were described as frequency or percentage and determine any statistical differences through chi-square tests. Binary logistic regression model was used to evaluate the associations between $\mathrm{CHM}$ treatment and depression status. Non-adjusted and multivariate adjusted models were all listed. When covariances added to this model and changed the matched odds ratio by at least $10 \%$, then the covariances should be adjusted according to the recommendation of STROBE statement ${ }^{[15]}$. Stratified linear regression models were used for the subgroup analyses. The likelihood ration test were be used to inspect the modification and interaction of subgroup.

All of the analyses were performed with the statistical software packages $\mathrm{R}$ (The R Foundation; http://www.r-project.org; version 3.4.3) and EmpowerStats (http://www.empowerstats.com, X\&Y Solutions, Inc., Boston, MA). P values less than 0.05 (two-sided) were considered statistically significant.

\section{Results}

\section{Baseline characteristics of participants}


A total of 809 cancer outpatients were recruited in this cross-sectional study from June 2020 to April 2021, 374 was enrolled in Received CHM treatment group and 435 was enrolled in Non-received CHM treatment group. The average age of the two group was $56.34 \pm 11.53$ years old and $57.19 \pm 12.57$ years old respectively. The ratio of depression status in Received CHM treatment group and Non-received CHM treatment group were $50.27 \%, 66.44 \%$ respectively. There were no statistically significant difference in age and gender among two groups. The difference was statistically significant in the distribution of medical insurance, ECOG PS, clinical stage, cancer type, metastasis, gene mutation, the classification of time since diagnosis, treatment plan, the classification of HAMD24 Score in two group(Table 1).

\section{The results of HAMD scores and HRQOL}

374 outpatients enrolled in the group of Received CHM treatment and 435 outpatients enrolled in the group of Non-received CHM treatment. HAMD scores in the Received CHM treatment group were significantly decreased compared to the group of Non-received CHM treatment $(P<0.001)$. Physical functioning, role functioning, emotional functioning, social functioning and global health status in the group of Received CHM treatment showed significantly higher mean than those in the group of Nonreceived $\mathrm{CHM}$ treatment $(P<0.05)$. Compared to the group of Received $\mathrm{CHM}$ treatment, symptoms including fatigue, nausea and vomiting, pain, dyspnea, insomnia, appetite loss, constipation, financial difficulties in the group of Non-received CHM treatment had significantly higher mean $(P<0.05)$. No significant differences were observed in cognitive functioning $(P=0.079)$ and diarrhea $(P=0.190)$ in the two group(Table 2).

\section{Univariate analysis}

The results of univariate analysis indicated gender, medical insurance, time since diagnosis, ECOG PS, cancer stage (III, IV), metastasis at diagnosis, gene mutation, adjuvant treatment were correlated with depression $(P<0.05)$. Age and cancer type were not associated with depression $(P>0.05)$ (Table 3$)$.

\section{The results of relationship between $\mathrm{CHM}$ treatment and depression}

The associations between $\mathrm{CHM}$ treatment and depression were evaluated by binary logistic regression model. In crude model, received $\mathrm{CHM}$ treatment indicated negative correlation with depression $(\mathrm{OR}=0.5$, 95\% confidence interval (CI): 0.4 to $0.7, \mathrm{P}<0.001)$. In Model I (adjusted for gender, metastasis at diagnosis, time since diagnosis), the result did not obviously change ( $\mathrm{OR}=0.7,95 \%$ confidence interval (Cl): 0.5 to $0.9, P=0.035)$. However, there were non-connection in Model II after adjusting gender, medical insurance, years since diagnosis, ECOG PS, cancer stage, metastasis at diagnosis, gene mutation, treatment plan at visit (OR=0.7, 95\% confidence interval $(\mathrm{Cl}): 0.5$ to 1.1, $\mathrm{P}=0.104)$. For the purpose of sensitivity analysis, we classified the duration of $\mathrm{CHM}$ treatment and handled as categorical variables. The same trend was found as well ( $P$ for trend were $<0.01,0.030,0.053$ in crude model, Model I, Model II respectively) (Table 4).

\section{The results of subgroup analyses}


As is shown in Table 5, the test for interactions in each subgroup were no significant for metastasis at diagnosis age, gender, medical insurance, time since diagnosis, ECOG PS, cancer stage, metastasis at diagnosis, gene mutation, treatment plan at visit ( $P$ for interaction $=0.14,0.93,0.32,0.57,0.23,0.15,0.86$, $0.05,0.69$ and 0.80 , respectively).

\section{Discussion}

The aim of the study was to investigate the relationship between $\mathrm{CHM}$ treatment and depression in cancer outpatients. The assessment results of HAMD and EORTC QLQ-C30 in Received CHM treatment group were better than Non-received $\mathrm{CHM}$ treatment group $(\mathrm{P}<0.05)$. $\mathrm{CHM}$ treatment was significantly negative associated with depression in Model I after adjusting related confounders ( $O R=0.7,95 \%$ confidence interval $(\mathrm{Cl})$ : 0.5 to $1.0, \mathrm{P}=0.035)$, while the sensitivity analysis were showed the same trend. The interactions in each subgroup were no significantly effect on the relationship between CHM treatment and depression $(P>0.05)$. The results indicated that $\mathrm{CHM}$ treatment can obviously relieve depression in cancer patients, thereby improve the quality of life. All in all, CHM treatment was an independent protective factor for depression in cancer patients combine with the results of hierarchical analysis.

In our study, the results showed that HAMD scores in the Received CHM treatment group were significantly decreased compared with Non-received $\mathrm{CHM}$ treatment group $(P<0.001)$. Although received $\mathrm{CHM}$ treatment could alleviate depression of cancer patients, the depression for cancer patients still persist. The possibility of tumor recurrence and a variety of adverse symptoms would caused depression in cancer patient during the development and progression of disease ${ }^{[16]}$. The Hamilton Depression Scale was often used in the clinical diagnosis of depression. However the recognized evaluation scale for depression status on cancer patients had not yet made, the Hamilton Depression Scale was still used in the clinical diagnosis of depression for cancer patients, and could great evaluate the patient's depression status $^{[17-18]}$. The quality of life in cancer patients had always been the focus of attention of clinicians. Thus several HRQoL tools have been developed and tested for the cancer population, including the European Organization for the Research and Treatment of Cancer QLQ-C30(EORTC QLQ-C30). Currently, EORTC QLQ-C30 were used extensively to measure quality of life in cancer patients in clinical trial ${ }^{[2]}$. Thus we used EORTC QLQ-C30 to assess the quality of life in cancer patients. In the analysis of HRQoL, those items include four functional scales (physical, role, emotionaland social), three symptom sub-scales (fatigue, pain, nausea and vomiting), one global health condition sub-scale and five individual measurement items (dyspnea, appetite, insomnia, constipation and economic status) in Received CHM treatment group were obviously better than Non-received CHM treatment group $(P<0.05)$. It could be seen that CHM treatment can improve the quality of life in cancer patients which were similar to that obtained by Wang $S$ et al ${ }^{[10]}$.

In order to further clarify the influence of CHM treatment on the depression status in cancer patients, we firstly determined some factors were related to the depression status in cancer patients through univariate analysis. The results showed gender, medical insurance, time since cancer diagnosis, 
ECOG PS, cancer stage (III, IV), metastasis at diagnosis, gene mutation, adjuvant treatment were correlated with depression status. Most of these results were consistent with the results of previous studies, and some are different ${ }^{[19-22]}$. Those discrepancy may be caused by differences in race, medical environment and understanding of tumors. Subsequently, we used binary logistic regression model to analyze the relationship between CHM treatment with depression status in cancer patients. After adjusting potential confounders (gender, medical insurance, years since diagnosis), the OR of CHM treatment was less than $1(\mathrm{P}<0.05)$ and the $\mathrm{OR}$ of duration of $\mathrm{CHM}$ treatment was gradually decreased, the $\mathrm{P}$ for trend was less than 0.05 . Although $\mathrm{P}$ was no statistical significant in adjusting full confounders (gender, medical insurance, years since diagnosis, ECOG PS, cancer stage, metastasis at diagnosis, gene mutation, treatment plan at visit), the OR was similar which means the relationship between $\mathrm{CHM}$ treatment and depression status is stable. The result of binary logistic regression model means $\mathrm{CHM}$ treatment was in cancer patients had a lower risk of depression ( $\mathrm{OR}=0.7,95 \% \mathrm{Cl}: 0.5$ to $0.9, \mathrm{P}=0.035)$. The exploration of subgroup analyses is extremely important for a scientific study. In this analyses, the results indicated each subgroup were no significantly effect on the relationship of $\mathrm{CHM}$ treatment and depression $(\mathrm{P}>0.05)$, which means the influence of $\mathrm{CHM}$ treatment on depression in cancer patients would not change due to confounding factors. Therefore, $\mathrm{CHM}$ treatment is an independent protective factor for depression in cancer patients.

Western medicine and TCM have their respective advantages in anti-tumor treatment. Although TCM is not understood by foreign scholars, it has been proved an explicit anti-tumor effect in clinical and basic research fields with the efforts of Chinese scholars. TCM, especially CHM including a single herb (such as Panax ginseng (Ren-Shen), Astragalus mongholicus Bunge (Huang-Qi,), Angelica sinensis (Oliv.) Diels (Dang-Gui)), compound formulation (such as Sijunzi-tang, Bu-zhong-yi-qi-tang, Shi-Quan-Da-Bu-Tang) and Chinese medicine preparation(such as Shenqi Fuzheng Injection, Kanglaite Injection) play a positive role in regulating the cancer immune system ${ }^{[10]}$. Moreover, $\mathrm{CHM}$ also plays its anti-cancer effects through apoptosis induction, proliferation inhibition, metastasis suppression, multidrug resistance reversal[23]. Related clinical studies indicated CHM treatment improved cancer patients' QoL and enhanced survival rate $^{[24-25]}$.

Depression is common in cancer patients, and poor metal health would be detrimental effect for physical wellbeing. Psychotherapy and antidepressant medication were treatment guidlines for depression. Regardless of the anti-tumor therapeutic effect of $\mathrm{CHM}, \mathrm{CHM}$ could be regarded as problem-solving therapy(PST) which was an important types of psychotherapy ${ }^{[26]}$. CHM treatment is deeply rooted in the Chinese people's ideology, so that most partical cancer patients in China seeked CHM treatment for relieving worry and anxiety about their illness whether or not recived western medicine therapy. Certainly, $\mathrm{CHM}$ could also anti-depression in addition to anti-tumor. CHM compound formulation(Xiaoyao Kangai Jieyu Fang) were effectively alleviating depression-like behaviors and tumor proliferation in vehicle mice ${ }^{[27]}$. $\mathrm{CHM}$ exerts its anti-depression through increasing synaptic concentrations of monoamines, alleviating the hypothalamic-pituitary-adrenal (HPA) axis dysfunctions, lightening the impairment of neuroplasticity, fighting towards immune and inflammatory dysregulation ${ }^{[28]}$. How does the depression 
status in cancer patients generate? There was a hypothesis that elevations in pro-inflammatory cytokines in cancer patients are capable of causing depression ${ }^{[4]}$. How does $\mathrm{CHM}$ works on the depression in cancer patients? We guess that $\mathrm{CHM}$ affect the depression status in cancer patients via antiinflammatory mechanisms. To verify this conjecture, further research is needed.

At present, there were many cross-sectional studies on the depression in cancer patients in China. However the relationship between CHM treatment and depression in cancer patients was not reported. This is the first study to explore the connection on CHM treatment and depression in cancer patients. Obviously, our study had some limitations. First, this study is an analytical cross-sectional study that merely provide weak evidence between exposure and outcome. Second, a selection biasis present since patients were recruited from one hospital. Finally, the sample size might be relatively small in our study. So we should be interpreted with prudent about our results. Interesting of the results in our study could generate hypotheses for further studies. In the future, more research such as expanding sample size, $\mathrm{CHM}$ treatment in other race/ethnic groups is needed to confirm our findings.

In conclusion, depression would affect the quality of life, compliance to treatment and disease advancement in cancer patients. We should pay attention to cancer-related depression in cancer patient. $\mathrm{CHM}$ treatment could improve quality of life and anti-cancer in reducing side effects of conventional treatment for cancer and improving immune system function. At present, antidepressant medicine was lack of relevant clinical evidence-based for curative effect on depression in cancer patients and effect on tumors, meanwhile relative studies showed medication of antidepressants were determined to cause adverse side effects ${ }^{[28]}$. Therefore, $\mathrm{CHM}$ can be a treatment for depression in cancer patients based on the above premise.

\section{Declarations}

\section{Funding:}

This study was supported by the Shanghai Municipal Health Commission and Shanghai Municipal Administrator of Traditional Chinese Medicine, Shanghai, China (No. shslczdzk03701).

\section{Conflicts of interest/Competing interests:}

The authors declare no potential conflicts of interest.

\section{Availability of data and material:}

The datasets generated and/or analysed during the current study are not publicly available due to the fact that the study is still ongoing on cancer populations, but are available from the corresponding author on reasonable request.

\section{Code availability:}


It are available from the corresponding author on reasonable request.

\section{Authors' contributions:}

Dr Wang had full access to all of the data in the study and takes responsibility for the integrity of the data and the accuracy of the data analysis.

Concept and design: Huiyue Lin, Juyong Wang

Acquisition, analysis, or interpretation of data: All authors

Drafting of the manuscript: Huiyue Lin

Critical revision of the manuscript for important intellectual content: All authors

Statistical analysis: Huiyue Lin, Juyong Wang

Administrative, technical, or material support: Juyong Wang

Supervision: Juyong Wang

Role of the Funder/Sponsor: The funder had no role in the design and conduct of the study; collection, management, analysis, and interpretation of the data; preparation, review, or approval of the manuscript; and decision to submit the manuscript for publication.

\section{Ethics approval:}

All experimental protocols were approved by Longhua Hospital Shanghai University of Traditional Chinese Medicine ethical committee (2020LCSY057).

\section{Consent to participate:}

Participants were fully informed of the purpose and procedures of the study and had the adequate time to ask questions and ponder about their voluntary participation. A written informed consent was obtained from all patients before enrollment.

\section{Consent for publication:}

we agree with publish our individual's data or image if the article can be published

\section{Acknowledgements:}

We would like to thank all students (namely Jianying Ma, Jiaying Xu)that helped us recruit patients at Longhua Hospital Shanghai University of Traditional Chinese Medicine (Shanghai, China). We would like to thank all the patients who participated in this study for their support and understanding of our work. 
We acknowledge the Shanghai Municipal Health Commission and Shanghai Municipal Administrator of Traditional Chinese Medicine, Shanghai, China for supporting our study (No. shslczdzk03701).

\section{References}

1. World Health Organization. Global cancer observatory. Available at: https://gco.iarc.fr/today/home.

2. Persky VW, Kempthorne-Rawson J, Shekelle RB. Personality and risk of cancer: 20-year follow-up of the Western Electric Study. Psychosom Med 1987; 49:435-449. https://doi.org/10.1097/00006842198709000-00001

3. Helgeson VS, Cohen S, Schulz R, et al. Group support interventions for women with breast cancer: who benefits from what. Health Psychol 2000; 19:107-114. https://doi.org/10.1037//02786133.19.2.107

4. Sotelo JL, Musselman D, Nemeroff C. The biology of depression in cancer and the relationship between depression and cancer progression. Int Rev Psychiatry 2014; 26:16-30. https://doi.org/10.3109/09540261.2013.875891

5. Tao WW, Jiang H, Tao XM, et al. Effects of Acupuncture, Tuina, Tai Chi, Qigong, and Traditional Chinese Medicine Five-Element Music Therapy on Symptom Management and Quality of Life for Cancer Patients: A Meta-Analysis. J Pain Symptom Manage 2016; 51:728-747. https://doi.org/10.1016/j.jpainsymman.2015.11.027

6. Ostuzzi G, Matcham F, Dauchy S, et al. Antidepressants for the treatment of depression in people with cancer. Cochrane Database Syst Rev 2015:CD011006.

7. Ng CG, Boks MP, Zainal NZ, et al. The prevalence and pharmacotherapy of depression in cancer patients. J Affect Disord 2011; 131:1-7. https://doi.org/10.1002/14651858.CD011006.pub2

8. Luo Y, Wang CZ, Hesse-Fong J, et al. Application of Chinese Medicine in Acute and Critical Medical Conditions. Am J Chin Med 2019; 47:1223-1235. https://doi.org/10.1142/S0192415X19500629

9. Xiang Y, Guo Z, Zhu P, et al. Traditional Chinese medicine as a cancer treatment: Modern perspectives of ancient but advanced science. Cancer Med 2019; 8:1958-1975. https://doi.org/10.1002/cam4.2108

10. Wang S, Long S, Deng Z, et al. Positive Role of Chinese Herbal Medicine in Cancer Immune Regulation. Am J Chin Med 2020; 48:1577-1592. https://doi.org/ 10.1142/S0192415X20500780.

11. Hamilton M. A rating scale for depression. J Neurol Neurosurg Psychiatry 1960; 23:56-62. https://doi.org/ 10.1136/jnnp.23.1.56

12. Aaronson NK, Ahmedzai S, Bergman B, et al. The European Organization for Research and Treatment of Cancer QLQ-C30: a quality-of-life instrument for use in international clinical trials in oncology. J Natl Cancer Inst 1993; 85:365-376. https://doi.org/10.1093/jnci/85.5.365

13. Zhao H, Kanda K. Testing psychometric properties of the standard Chinese version of the European Organization for Research and Treatment of Cancer Quality of Life Core Questionnaire 30 (EORTC QLQ-C30). J Epidemiol 2004; 14:193-203. https://doi.org/10.2188/jea.14.193 
14. Eberst G, Anota A, Scherpereel A, et al. Health-Related Quality of Life Impact from Adding Bevacizumab to Cisplatin-Pemetrexed in Malignant Pleural Mesothelioma in the MAPS IFCT-GFPC0701 Phase III Trial. Clin Cancer Res. 2019; 25:5759-5765. https://doi.org/ 10.1158/1078-0432.CCR$18-2860$

15. Kernan WN, Viscoli CM, Brass LM, et al. Phenylpropanolamine and the risk of hemorrhagic stroke. N Engl J Med.2000; 343:1826-1832. https://doi.org/10.1056/NEJM200012213432501

16. Tao W, Luo X, Cui B, et al. Practice of traditional Chinese medicine for psycho-behavioral intervention improves quality of life in cancer patients: A systematic review and meta-analysis. Oncotarget. 2015;6: 39725-39739. https://doi.org/10.18632/oncotarget.5388

17. Zhang $S$, Chen $H$, Zhang $M$, et al. Reduction of depression symptoms in laryngeal cancer patients receiving psychology services. Am J Transl Res 2020; 12:6637-6645. PMID: 33194060

18. Li M, Kouzmina E, McCusker M, et al. Cytokines and depression in cancer patients and caregivers. Neuropsychiatr Dis Treat. 2017; 13:2903-2911. https://doi.org/10.2147/NDT. S144774

19. Linden W, Vodermaier A, Mackenzie R, et al. Anxiety and depression after cancer diagnosis: prevalence rates by cancer type, gender, and age. J Affect Disord 2012; 141:343-351. https://doi.org/10.1016/j.jad.2012.03.025

20. Tsaras K, Papathanasiou IV, Mitsi D, et al. Assessment of Depression and Anxiety in Breast Cancer Patients: Prevalence and Associated Factors. Asian Pac J Cancer Prev. 2018; 19:1661-1669. https://doi.org/10.22034/APJCP.2018.19.6.1661

21. Korsten LHA, Jansen F, de Haan BJF, et al. Factors associated with depression over time in head and neck cancer patients: A systematic review. Psychooncology. 2019; 28:1159-1183. https://doi.org/10.1002/pon.5058

22. Götze $H$, Friedrich $M$, Taubenheim $S$, et al. Depression and anxiety in long-term survivors 5 and 10 years after cancer diagnosis. Support Care Cancer 2020; 28:211-220. https://doi.org/10.1007/s00520-019-04805-1

23. Yan Z, Lai Z, Lin J. Anticancer Properties of Traditional Chinese Medicine. Comb Chem High Throughput Screen 2017; 20:423-429. https://doi.org/10.2174/1386207320666170116141818

24. Jiang Y, Liu LS, Shen LP, et al. Traditional Chinese Medicine treatment as maintenance therapy in advanced non-small-cell lung cancer: A randomized controlled trial. Complement Ther Med. 2016; 24:55-62. https://doi.org/10.1016/j.ctim.2015.12.006

25. Liu CT, Chen YH, Huang YC, et al. Chemotherapy in conjunction with traditional Chinese medicine for survival of patients with early female breast cancer: protocol for a non-randomized, single center prospective cohort study. Trials 2019; 20:741. https://doi.org/10.1186/s13063-019-3848-8

26. Cuijpers P, Quero S, Dowrick C, Arroll B. Psychological Treatment of Depression in Primary Care: Recent Developments. Curr Psychiatry Rep. 2019 Nov 23;21(12):129. https://doi.org/10.1007/s11920-019-1117-x

27. Meng P, Han Y, Yang Q, et al. Xiaoyao Kangai Jieyu Fang, a Chinese Herbal Formulation, Ameliorates Cancer-Related Depression Concurrent with Breast Cancer in Mice via Promoting Hippocampal 
Synaptic Plasticity. Evid Based Complement Alternat Med. 2018; 2018:3967642.

https://doi.org/10.1155/2018/3967642

28. Wang YS, Shen CY, Jiang JG. Antidepressant active ingredients from herbs and nutraceuticals used in TCM: pharmacological mechanisms and prospects for drug discovery. Pharmacol Res 2019; 150:104520. https://doi.org/10.1142/S0192415X20500780

\section{Tables}

Table 1. Baseline Characteristics of participants $(\mathrm{N}=809)$ 


\begin{tabular}{|c|c|c|c|}
\hline \multirow[b]{2}{*}{ Characteristics } & \multicolumn{3}{|c|}{ CHM treatment } \\
\hline & Received & Non-received & P-value \\
\hline Number & 374 & 435 & \\
\hline Age (years, Mean \pm SD) & $\begin{array}{l}57.19 \pm \\
12.57\end{array}$ & $56.34 \pm 11.53$ & 0.317 \\
\hline Medical insurance, n (\%) & & & $<0.001$ \\
\hline Self-financed patient & $117(31.28)$ & $229(52.64)$ & \\
\hline Medicare patient & $257(68.72)$ & $206(47.36)$ & \\
\hline Gender, n (\%) & & & 0.539 \\
\hline Female & $253(67.65)$ & $303(69.66)$ & \\
\hline Male & $121(32.35)$ & $132(30.34)$ & \\
\hline ECOG PS, n (\%) & & & $<0.001$ \\
\hline$<1$ & $245(65.51)$ & $202(46.44)$ & \\
\hline$\geq 1$ & $129(34.49)$ & $233(53.56)$ & \\
\hline Clinical stage at study entry ${ }^{a}, \mathrm{n}(\%)$ & & & $<0.001$ \\
\hline I & $235(62.83)$ & $172(39.54)$ & \\
\hline II & $81(21.66)$ & $95(21.84)$ & \\
\hline III & $30(8.02)$ & 78 (17.93) & \\
\hline IV & $28(7.49)$ & $90(20.69)$ & \\
\hline Cancer type, n (\%) & & & 0.040 \\
\hline Lung Cancer & $174(46.52)$ & $226(51.95)$ & \\
\hline Breast Cancer & $98(26.20)$ & $92(21.15)$ & \\
\hline Thyroid Cancer & $54(14.44)$ & $43(9.89)$ & \\
\hline Digestive system tumors ${ }^{b}$ & $32(8.56)$ & $43(9.89)$ & \\
\hline Other types of cancer ${ }^{c}$ & $16(4.28)$ & $31(7.13)$ & \\
\hline Metastasis at diagnosis, $\mathbf{n}(\%)$ & & & $<0.001$ \\
\hline No & $270(72.19)$ & $209(48.05)$ & \\
\hline Yes & $104(27.81)$ & $226(51.95)$ & \\
\hline Gene mutation, $n(\%)$ & & & $<0.001$ \\
\hline
\end{tabular}


Untested

Yes

The classification of time since diagnosis(months), $n$

(\%)

$\leq 3$

$3-11$

$11-26$

$\mathrm{T}>26$

Treatment plan at visit, $\mathbf{n}(\%)$

Without other treatment

Adjuvant treatment ${ }^{d}$

Endocrine treatment ${ }^{\mathrm{e}}$

The classification of HAMD24 Score, $n(\%)$

Score $\leq 8$

Score $>8$

Abbreviations: CHM, Chinese herbal medicine; ECOG PS, Eastern Cooperative Oncology Group performance status. HAMD, Hamilton depression scale;

Nominally significant $p$ values $(P<0.05)$ are denoted in bold.

${ }^{\text {a }}$ Clinical stage classified on the basis of on the American Joint Committee on Cancer $7^{\text {th }}$ edition staging system.

${ }^{b}$ Digestive system tumors included gastric carcinoma[colorectal carcinoma[hepatocarcinoma[

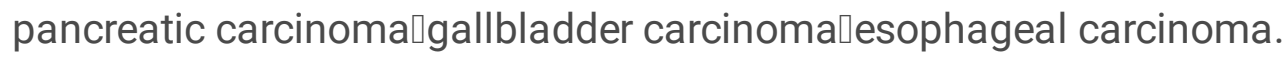

${ }^{c}$ Other types of cancer included ovarian carcinoma $\square$ cervical carcinoma $\square$ bladder carcinoma $\square$ non-Hodgkin's lymphoma.

${ }^{\mathrm{d}}$ Adjuvant treatment included chemotherapy $\square$ radiotherapy $\square$ targeted therapy $\square$ immunotherapy.

${ }^{\mathrm{e}}$ Endocrine treatment included oestrogen therapy $\square$ thyroid stimulating hormone suppression therapy.

Table 2. The results of HAMD scores and HRQoL 


\begin{tabular}{|c|c|c|c|c|c|c|c|}
\hline \multirow[b]{2}{*}{ Outcomes } & \multicolumn{3}{|c|}{ Received CHM treatment } & \multicolumn{3}{|c|}{ Non-received $\mathrm{CHM}$ treatment } & \multirow{2}{*}{$\begin{array}{l}P \\
\text { value }\end{array}$} \\
\hline & $\mathrm{N}$ & Mean(SD) & $\begin{array}{l}\text { Median(Q1- } \\
\text { Q3) }\end{array}$ & $\mathrm{N}$ & Mean(SD) & $\begin{array}{l}\text { Median(Q1- } \\
\text { Q3) }\end{array}$ & \\
\hline HAMD scores & 374 & $9.9(5.2)$ & $9.0(5.0-12.0)$ & 435 & $11.7(5.9)$ & $\begin{array}{l}11.0(8.0- \\
15.0)\end{array}$ & $<0.001$ \\
\hline \multicolumn{8}{|l|}{ EORTC QLQ-C30 } \\
\hline $\begin{array}{l}\text { Physical } \\
\text { functioning }\end{array}$ & 374 & $84.0(13.2)$ & $\begin{array}{l}86.7(80.0- \\
93.3)\end{array}$ & 435 & $81.6(15.3)$ & $\begin{array}{l}86.7(73.3- \\
93.3)\end{array}$ & 0.040 \\
\hline Role functioning & 374 & $91.3(15.5)$ & $\begin{array}{l}100.0(83.3- \\
100.0)\end{array}$ & 435 & $81.9(22.0)$ & $\begin{array}{l}100.0(66.7- \\
100.0)\end{array}$ & $<0.001$ \\
\hline $\begin{array}{l}\text { Emotional } \\
\text { functioning }\end{array}$ & 374 & $85.5(14.4)$ & $\begin{array}{l}91.7(81.2- \\
100.0)\end{array}$ & 435 & 78.2(17.0) & $\begin{array}{l}83.3(66.7- \\
91.7)\end{array}$ & $<0.001$ \\
\hline $\begin{array}{l}\text { Cognitive } \\
\text { functioning }\end{array}$ & 374 & 82.1(16.0) & $\begin{array}{l}83.3(66.7- \\
100.0)\end{array}$ & 435 & $80.0(17.1)$ & $\begin{array}{l}83.3(66.7- \\
100.0)\end{array}$ & 0.079 \\
\hline $\begin{array}{l}\text { Social } \\
\text { functioning }\end{array}$ & 374 & $90.2(16.0)$ & $\begin{array}{l}100.0(66.7- \\
100.0)\end{array}$ & 435 & $81.5(21.2)$ & $\begin{array}{l}100.0(66.7- \\
100.0)\end{array}$ & $<0.001$ \\
\hline $\begin{array}{l}\text { Global health } \\
\text { status }\end{array}$ & 374 & 70.3(12.5) & $\begin{array}{l}66.7(66.7- \\
83.3)\end{array}$ & 435 & $67.5(14.2)$ & $\begin{array}{l}\text { 66.7(66.7- } \\
83.3)\end{array}$ & 0.003 \\
\hline Fatigue & 374 & 23.2(20.9) & $\begin{array}{l}22.2(0.0- \\
33.3)\end{array}$ & 435 & $31.9(20.8)$ & $\begin{array}{l}33.3(11.1- \\
44.4)\end{array}$ & $<0.001$ \\
\hline $\begin{array}{l}\text { Nausea and } \\
\text { vomiting }\end{array}$ & 374 & 3.7(13.3) & $0.0(0.0-0.0)$ & 435 & $4.7(12.8)$ & $0.0(0.0-0.0)$ & 0.026 \\
\hline Pain & 374 & $12.0(20.3)$ & $0.0(0.0-16.7)$ & 435 & 15.4(17.5) & $\begin{array}{l}16.7(0.0- \\
33.3)\end{array}$ & $<0.001$ \\
\hline Dyspnea & 374 & 11.3(19.2) & $0.0(0.0-33.3)$ & 435 & $16.0(21.1)$ & $\begin{array}{l}0.0(0.0- \\
33.3)\end{array}$ & $<0.001$ \\
\hline Insomnia & 374 & $24.8(27.6)$ & $\begin{array}{l}33.3(0.0- \\
33.3)\end{array}$ & 435 & $31.6(29.6)$ & $\begin{array}{l}33.3(0.0- \\
66.7)\end{array}$ & 0.001 \\
\hline Appetite loss & 374 & $6.7(17.1)$ & $0.0(0.0-0.0)$ & 435 & 13.0(21.8) & $\begin{array}{l}0.0(0.0- \\
33.3)\end{array}$ & $<0.001$ \\
\hline Constipation & 374 & 6.1(16.3) & $0.0(0.0-0.0)$ & 435 & 10.7(19.8) & $\begin{array}{l}0.0(0.0- \\
33.3)\end{array}$ & $<0.001$ \\
\hline Diarrhea & 374 & 8.0(18.0) & $0.0(0.0-0.0)$ & 435 & $6.6(16.4)$ & $0.0(0.0-0.0)$ & 0.190 \\
\hline $\begin{array}{l}\text { Financial } \\
\text { difficulties }\end{array}$ & 374 & $9.8(17.2)$ & $0.0(0.0-33.3)$ & 435 & 13.9(19.7) & $\begin{array}{l}0.0(0.0- \\
33.3)\end{array}$ & $<0.001$ \\
\hline
\end{tabular}

Nominally significant $p$ values $(P<0.05)$ are denoted in bold. 
Abbreviations: CHM, Chinese herbal medicine; HAMD, Hamilton depression scale; EORTC QLQ-C30, The European Organization for Research and Treatment of Cancer (EORTC) Core Quality of Life Questionnaire (QLQ-C30).

Table 3. Univariate analysis for depression 


\begin{tabular}{|c|c|c|c|}
\hline Covariate & Statistics & OR $(95 \% \mathrm{Cl})$ & $P$-value \\
\hline Age, year & $56.7 \pm 12.0$ & $1.0(1.0,1.0)$ & 0.940 \\
\hline \multicolumn{4}{|l|}{ Gender } \\
\hline Female & $556(68.7 \%)$ & Refrence & \\
\hline Male & $253(31.3 \%)$ & $0.6(0.5,0.9)$ & 0.003 \\
\hline \multicolumn{4}{|l|}{ Medical insurance } \\
\hline Self-financed patient & $346(42.8 \%)$ & Refrence & \\
\hline Medicare patient & $463(57.2 \%)$ & $0.7(0.5,0.9)$ & 0.004 \\
\hline \multicolumn{4}{|c|}{ The classification of time since diagnosis, months } \\
\hline$\leq 3$ & $200(24.7 \%)$ & Refrence & \\
\hline $3-11$ & $185(22.9 \%)$ & $0.5(0.3,0.8)$ & 0.003 \\
\hline $11-26$ & 215 (26.6\%) & $0.5(0.3,0.7)$ & $<0.001$ \\
\hline$>26$ & $209(25.8 \%)$ & $0.5(0.3,0.8)$ & $<0.001$ \\
\hline \multicolumn{4}{|l|}{ ECOG PS } \\
\hline$<1$ & $447(55.3 \%)$ & Refrence & \\
\hline$\geq 1$ & $362(44.7 \%)$ & $1.6(1.2,2.1)$ & 0.002 \\
\hline \multicolumn{4}{|l|}{ Cancer stage } \\
\hline I & 407 (50.3\%) & Refrence & \\
\hline II & $176(21.8 \%)$ & $1.3(0.9,1.8)$ & 0.169 \\
\hline III & $108(13.3 \%)$ & $1.6(1.0,2.4)$ & 0.046 \\
\hline IV & $118(14.6 \%)$ & $1.9(1.2,2.9)$ & 0.005 \\
\hline \multicolumn{4}{|l|}{ Cancer type } \\
\hline Lung cancer & $400(49.4 \%)$ & Refrence & \\
\hline Breast cancer & $190(23.5 \%)$ & $1.1(0.8,1.5)$ & 0.682 \\
\hline Thyroid cancer & $97(12.0 \%)$ & $0.9(0.6,1.4)$ & 0.581 \\
\hline Digestive system tumors & $75(9.3 \%)$ & $0.9(0.6,1.6)$ & 0.819 \\
\hline Other cancer & $47(5.8 \%)$ & $1.2(0.7,2.3)$ & 0.503 \\
\hline \multicolumn{4}{|l|}{ Metastasis at diagnosis } \\
\hline No & 479 (59.2\%) & Refrence & \\
\hline
\end{tabular}




\begin{tabular}{|llll|}
\hline Yes & $330(40.8 \%)$ & $1.6(1.2,2.2)$ & 0.001 \\
\hline Untested & & & \\
\hline Yes & $674(83.3 \%)$ & Refrence & \\
\hline Treatment plan at visit & $135(16.7 \%)$ & $1.8(1.2,2.7)$ & 0.003 \\
\hline Without other treatment & & & \\
\hline Adjuvant treatment & $494(61.1 \%)$ & Refrence & \\
\hline Endocrine treatment & $139(17.2 \%)$ & $1.8(1.2,2.6)$ & 0.006 \\
\hline
\end{tabular}

Nominally significant $p$ values $(P<0.05)$ are denoted in bold.

Abbreviations: ECOG PS, Eastern Cooperative Oncology Group performance status; $\mathrm{Cl}$, confidence interval; $\mathrm{OR}$, odds ratio

Table 4. Relationship between CHM treatment with depression 


\begin{tabular}{|c|c|c|c|c|c|c|}
\hline \multirow[b]{2}{*}{ Variable } & \multicolumn{2}{|c|}{ Crude Model } & \multicolumn{2}{|l|}{ Model I } & \multicolumn{2}{|l|}{ Model II } \\
\hline & $\begin{array}{l}\text { OR } \\
(95 \% \mathrm{Cl})\end{array}$ & $\begin{array}{l}\mathrm{P}- \\
\text { value }\end{array}$ & $\begin{array}{l}\mathrm{OR} \\
(95 \% \mathrm{Cl})\end{array}$ & $\begin{array}{l}\mathrm{P}- \\
\text { value }\end{array}$ & $\begin{array}{l}\text { OR } \\
(95 \% \mathrm{Cl})\end{array}$ & $\begin{array}{l}\mathrm{P} \text { - } \\
\text { value }\end{array}$ \\
\hline \multicolumn{7}{|c|}{ CHM treatment } \\
\hline Non-received & Refrence & & Refrence & & Refrence & \\
\hline Received & $\begin{array}{l}0.5(0.4 \\
0.7)\end{array}$ & $<0.001$ & $\begin{array}{l}0.7(0.5 \\
1.0)\end{array}$ & 0.035 & $\begin{array}{l}0.7(0.5 \\
1.1)\end{array}$ & 0.104 \\
\hline \multicolumn{7}{|c|}{$\begin{array}{l}\text { Duration of CHM Treatment } \\
\text { पmonths } \square\end{array}$} \\
\hline 0 & Refrence & & Refrence & & Refrence & \\
\hline$\leq 6$ & $\begin{array}{l}0.7(0.4 \\
1.1)\end{array}$ & 0.095 & $\begin{array}{l}0.9(0.6 \\
1.5)\end{array}$ & 0.704 & $\begin{array}{l}1.0(0.6 \\
1.6)\end{array}$ & 0.957 \\
\hline $6-12$ & $\begin{array}{l}0.4(0.3 \\
0.7)\end{array}$ & $<0.001$ & $\begin{array}{l}0.5(0.3 \\
0.9)\end{array}$ & 0.017 & $\begin{array}{l}0.5(0.3 \\
0.9)\end{array}$ & 0.031 \\
\hline $12-24$ & $\begin{array}{l}0.5(0.3 \\
0.7)\end{array}$ & 0.001 & $\begin{array}{l}0.5(0.3 \\
0.9)\end{array}$ & 0.029 & $\begin{array}{l}0.6(0.3 \\
1.0)\end{array}$ & 0.065 \\
\hline$>24$ & $\begin{array}{l}0.5(0.3 \\
0.7)\end{array}$ & $<0.001$ & $\begin{array}{l}0.5(0.3 \\
1.0)\end{array}$ & 0.060 & $\begin{array}{l}0.6(0.3 \\
1.1)\end{array}$ & 0.095 \\
\hline$P$ for trend & & $<0.001$ & & 0.030 & & 0.053 \\
\hline
\end{tabular}

Nominally significant pvalues $(P<0.05)$ are denoted in bold.

Abbreviations: $\mathrm{CHM}$, Chinese herbal medicine; $\mathrm{Cl}$, confidence interval; $\mathrm{OR}$, odds ratio

Model I adjusted for gender, metastasis at diagnosis, time since diagnosis

Mode II adjusted for gender, medical insurance, years since diagnosis, ECOG PS, cancer stage, metastasis at diagnosis, gene mutation, treatment plan at visit

Table 5. Effect size of CHM treatment on depression in prespecified and exploratory subgroups in Each Subgroup 


\begin{tabular}{|c|c|c|c|c|c|}
\hline \multirow[b]{2}{*}{ Characteristic } & \multicolumn{2}{|c|}{ CHM treatment (n) } & \multirow{2}{*}{$\begin{array}{l}\text { OR } \\
(95 \% \mathrm{Cl})\end{array}$} & \multirow{2}{*}{$\begin{array}{l}P \\
\text { value }\end{array}$} & \multirow{2}{*}{$\begin{array}{l}\text { P for } \\
\text { interaction }\end{array}$} \\
\hline & Received & $\begin{array}{l}\text { Non- } \\
\text { received }\end{array}$ & & & \\
\hline Age(years) & & & & & 0.14 \\
\hline$<51$ & 105 & 146 & $\begin{array}{l}0.9(0.5 \\
1.7)\end{array}$ & 0.701 & \\
\hline $51-62$ & 122 & 140 & $\begin{array}{l}1.0(0.5 \\
2.1)\end{array}$ & 0.961 & \\
\hline$>62$ & 147 & 149 & $\begin{array}{l}0.4(0.2 \\
0.8)\end{array}$ & 0.013 & \\
\hline Gender & & & & & 0.93 \\
\hline Female & 253 & 303 & $\begin{array}{l}0.8(0.5 \\
1.2)\end{array}$ & 0.288 & \\
\hline Male & 121 & 132 & $\begin{array}{l}0.6(0.3 \\
1.3)\end{array}$ & 0.195 & \\
\hline Medical insurance & & & & & 0.32 \\
\hline Self-financed patient & 117 & 229 & $\begin{array}{l}0.6(0.3 \\
1.1)\end{array}$ & 0.096 & \\
\hline Medicare patient & 257 & 206 & $\begin{array}{l}0.9(0.5 \\
1.6)\end{array}$ & 0.779 & \\
\hline $\begin{array}{l}\text { The classification of time since } \\
\text { diagnosis(months) }\end{array}$ & & & & & 0.57 \\
\hline$\leq 3$ & 13 & 187 & $\begin{array}{l}0.6(0.2 \\
2.3)\end{array}$ & 0.445 & \\
\hline $3-11$ & 55 & 130 & $\begin{array}{l}1.0(0.5 \\
2.0)\end{array}$ & 0.918 & \\
\hline $11-26$ & 146 & 69 & $\begin{array}{l}0.6(0.3 \\
1.3)\end{array}$ & 0.204 & \\
\hline $\mathrm{T}>26$ & 160 & 49 & $\begin{array}{l}0.7(0.3 \\
1.7)\end{array}$ & 0.470 & \\
\hline ECOG PS & & & & & 0.23 \\
\hline$<1$ & 245 & 202 & $\begin{array}{l}0.9(0.5 \\
1.5)\end{array}$ & 0.638 & \\
\hline$\geq 1$ & 129 & 233 & $\begin{array}{l}0.6(0.3 \\
1.1)\end{array}$ & 0.077 & \\
\hline Cancer stage & & & & & 0.15 \\
\hline
\end{tabular}




\begin{tabular}{|c|c|c|c|c|c|}
\hline I & 235 & 172 & $\begin{array}{l}0.6(0.3 \\
1.1)\end{array}$ & 0.111 & \\
\hline II & 81 & 95 & $\begin{array}{l}1.3(0.6, \\
2.9)\end{array}$ & 0.458 & \\
\hline III & 30 & 78 & $\begin{array}{l}0.4(0.1, \\
1.4)\end{array}$ & 0.152 & \\
\hline IV & 28 & 90 & $\begin{array}{l}0.6(0.2, \\
1.9)\end{array}$ & 0.412 & \\
\hline Cancer type & & & & & 0.86 \\
\hline Lung cancer & 174 & 226 & $\begin{array}{l}0.6(0.3, \\
1.0)\end{array}$ & 0.056 & \\
\hline Breast cancer & 98 & 92 & $\begin{array}{l}1.0(0.4, \\
2.1)\end{array}$ & 0.905 & \\
\hline Thyroid cancer & 54 & 43 & $\begin{array}{l}1.3(0.4, \\
4.6)\end{array}$ & 0.658 & \\
\hline Digestive system tumors & 32 & 43 & $\begin{array}{l}3.6(0.3, \\
24.1)\end{array}$ & 0.195 & \\
\hline Other cancer & 16 & 31 & $\begin{array}{l}0.2(0.0, \\
2.5)\end{array}$ & 0.191 & \\
\hline Metastasis at diagnosis & & & & & 0.05 \\
\hline No & 270 & 209 & $\begin{array}{l}0.6(0.4, \\
1.0)\end{array}$ & 0.072 & \\
\hline Yes & 104 & 226 & $\begin{array}{l}0.9(0.5, \\
1.7)\end{array}$ & 0.768 & \\
\hline Gene mutation & & & & & 0.69 \\
\hline Untested & 341 & 333 & $\begin{array}{l}0.8(0.5, \\
1.2)\end{array}$ & 0.361 & \\
\hline Yes & 33 & 102 & $\begin{array}{l}0.6(0.2, \\
1.9)\end{array}$ & 0.387 & \\
\hline Treatment plan at visit & & & & & 0.80 \\
\hline Without other treatment & 253 & 241 & $\begin{array}{l}0.7(0.5 \\
1.2)\end{array}$ & 0.230 & \\
\hline Adjuvant treatment & 30 & 109 & $\begin{array}{l}0.5(0.2, \\
1.5)\end{array}$ & 0.229 & \\
\hline Endocrine treatment & 91 & 85 & $\begin{array}{l}1.5(0.6, \\
3.5)\end{array}$ & 0.373 & \\
\hline
\end{tabular}

Nominally significant $p$ values $(P<0.05)$ are denoted in bold. 
Abbreviations: CHM, Chinese herbal medicine; ECOG, Eastern Cooperative Oncology Group; $\mathrm{Cl}$, confidence interval; OR, odds ratio.

Adjusted for age, gender, medical insurance, time since diagnosis, ECOG PS, cancer stage, metastasis at diagnosis, gene mutation, treatment plan at visit except the subgroup variable. 